IZA DP No. 8679

Are Pornography and Marriage Substitutes for Young Men?

Michael Malcolm

George Naufal

November 2014 


\title{
Are Pornography and Marriage Substitutes for Young Men?
}

\author{
Michael Malcolm \\ West Chester University of Pennsylvania \\ George Naufal \\ Timberlake Consultants \\ and IZA
}
Discussion Paper No. 8679
November 2014

\author{
IZA \\ P.O. Box 7240 \\ 53072 Bonn \\ Germany \\ Phone: +49-228-3894-0 \\ Fax: +49-228-3894-180 \\ E-mail: iza@iza.org
}

Any opinions expressed here are those of the author(s) and not those of IZA. Research published in this series may include views on policy, but the institute itself takes no institutional policy positions. The IZA research network is committed to the IZA Guiding Principles of Research Integrity.

The Institute for the Study of Labor (IZA) in Bonn is a local and virtual international research center and a place of communication between science, politics and business. IZA is an independent nonprofit organization supported by Deutsche Post Foundation. The center is associated with the University of Bonn and offers a stimulating research environment through its international network, workshops and conferences, data service, project support, research visits and doctoral program. IZA engages in (i) original and internationally competitive research in all fields of labor economics, (ii) development of policy concepts, and (iii) dissemination of research results and concepts to the interested public.

IZA Discussion Papers often represent preliminary work and are circulated to encourage discussion. Citation of such a paper should account for its provisional character. A revised version may be available directly from the author. 
IZA Discussion Paper No. 8679

November 2014

\section{ABSTRACT}

\section{Are Pornography and Marriage Substitutes for Young Men?}

Substitutes for marital sexual gratification may impact the decision to marry. Proliferation of the Internet has made pornography an increasingly low-cost substitute. We investigate the effect of Internet usage, and of pornography consumption specifically, on the marital status of young men. We show that increased Internet usage is negatively associated with marriage formation. Pornography consumption specifically has an even stronger effect. Instrumental variables and a number of robustness checks suggest that the effect is causal.

JEL Classification: J12, O33

Keywords: pornography, divorce, marital formation

Corresponding author:

George Naufal

Timberlake Consultants

B3 Broomsleigh Business Park

Worsley Bridge Road

London SE26 5BN

United Kingdom

E-mail: georgenaufal@timberlake.co.uk 


\section{Introduction}

The United States has seen considerable demographic changes with respect to family arrangements over the last few decades. Between 1950 and 2010, the rate of marital formation dropped by $39 \%$, with a $17 \%$ drop between 2000 and 2010 alone. ${ }^{1}$ Today, the proportion of men between 25 and 34 years old who have never been married is more than six times higher than it was in 1970. For men between 35 and 44 years old, the increase has been more than fourfold. Marriages that do form are about twice as likely to end in divorce today as in 1950.

Traditionally, one of the reasons to enter into a marriage was sexual gratification. But as options for sexual gratification outside of marriage have grown, the need for a marriage to serve this function is diminishing. The NIH reports that the fraction of 20 year-olds who have engaged in premarital sex grew by about $50 \%$ between the late 1950 s and the late 1990 s. Besides

premarital sex, another option is consumption of pornography, which has become widely more accessible since the proliferation of the Internet.

The degree to which these extra-marital options for sexual gratification substitute for marriage is an open question. Friedman (2000), among others, has suggested that one of the reasons that prostitution is so socially abhorrent is that it competes with women who seek a stable marriage. While there is a small literature on the relationship between prostitution and marriage, there is almost no empirical work on the substitutability between pornography and marriage. This paper attempts to fill the gap.

The proliferation of the Internet in the late 1990s and early 2000s was very rapid. The Census Bureau reports that in 1996 only $9.4 \%$ of Americans had accessed the Internet at all

\footnotetext{
${ }^{1}$ All aggregate statistics are from NCHS tables.
} 
within the 30 days prior to the survey. By 1998, 26.2\% of Americans had an Internet connection in their homes. This grew to $50.5 \%$ in 2001 and in 2010 stood at $71.1 \%$. A sizeable portion of the Internet is pornographic content. Forbes Magazine reports that, between July 2009 and July $2010,13 \%$ of all Internet searches were for erotic content. About $4 \%$ of the million most heavily visited sites are pornography websites. Estimates of the industry’s size vary, but $\$ 3$ billion a year for the US is a commonly reported figure. Estimates of pornography usage vary as well, but Carroll et al. (2008) claim that $87 \%$ of young adult males use pornography. ${ }^{2}$

Since changes in the accessibility of pornography have occurred coincident to large changes in marital behavior, the causal relationship between the two is a natural question. Between 2000 and 2004, the General Social Survey (GSS) asked a series of detailed questions about Internet usage; it also records comprehensive demographic information, including marital status. Using these microdata we find that for young men there is a large degree of substitutability between Internet and pornography usage and marriage - heavy Internet usage generally, and use of pornography specifically, are associated with lower participation in marriages. We employ instrumental variables and a number of robustness checks, all of which suggest that this is a causal effect and not merely the endogenous relationship that married men are less likely to look at pornography, or some kind of unobserved selection issue that distinguishes men who use pornography from men who do not use pornography.

We assert that increasing ease of accessing pornography is an important factor underlying the decline in marriage formation and stability. As policymakers seek to understand rapidly evolving family structures, technological change is surely an important element of these shifts.

\footnotetext{
${ }^{2}$ Interestingly, only $67 \%$ of young men believe that it is acceptable to use pornography.
} 
Specifically, to the extent that policymakers treat family arrangements as a control variable important for social welfare, and with a number of open public policy questions relating to web access, understanding the underlying the connection between the two is critical.

The paper proceeds as follows. Part II reviews the relevant literature on pornography and marriage and on extra-marital sexual substitutes for marriage generally. Part III presents a theoretical model of the relationship between the cost of accessing pornography, marriage formation and divorce. Part IV discusses data and methods. Part V presents the results and Part VI concludes.

\section{Related Literature}

Friedman (2000) says, of prostitution:

Laws making sex outside of marriage illegal improve the bargaining position of women who want to get married, or stay married, or to maintain a strong bargaining position within marriage. Hence it is rational for women to support such laws. It may also be rational for at least some men to support them...A longer-term result of access to sex without marriage may be a partial breakdown of the institution of marriage. If, as seems to be the case, children brought up by two parents end up on average as better people, more valuable trading partners and fellow citizens, than children brought up by one, preserving the institution of marriage may be desirable for men as well as women.

This speaks well to the dual purpose of our paper: extra-marital sexual opportunities can reduce marital formation and stability, and this is an important point for policymakers and for society at large since marital formation is generally regarded in a positive light.

Existing literature on prostitution generally assumes, at least implicitly, that prostitution substitutes for other ways of obtaining sex. Cameron and Collins (2003) assert that, for single men, the search cost of finding sexual partners is an important determinant of whether a man 
chooses a relationship or paid sex. Pitts et al. (2004) report that $36.4 \%$ of men who paid for sex did so because "paying for sex is less trouble". Along similar lines, Thorbek and Pattanaik (2002) find that many men who engage in sex tourism do so, by their own admission, because they do not want to invest in a stable relationship. Della Giusta et al. (2009A) find that demand for paid sex comes from two different groups: "regulars", whose demand for paid sex fits the profile described above, but also "experimenters", for whom paid sex is actually complementary to stable relationships by giving these men more diverse sexual opportunities. VanLandingham et al. (1993) find that a very large proportion of young Thai males solicit prostitutes, many because they lack a stable relationship; they also find long-term consequences for later behavior within marriage. In Della Giusta et al. (2009B), a theoretical analysis, the stigma effect associated with prostitution falls as its frequency rises. We should note here that, looking at the other side of the market, prostitutes are generally stigmatized. In fact, Edlund and Korn (2002) attribute high wages paid to prostitutes to the corresponding loss in marriage market opportunities.

A higher perceived cost among men of obtaining sex within a relationship appears to be associated with increased use of prostitutes. On the other side of this marginal cost / marginal benefit calculation, a decline in the cost of paid sex can also increase use of prostitutes. Cunningham and Kendall (2009) argue that the availability of online solicitation has resulted in a net increase in prostitution, not just a displacement of street prostitutes.

By contrast, there is relatively little research on the relationship between marriage and pornography. D’Orlando (2011) presents a theoretical model of pornography consumption in an attempt to explain the well-acknowledged habituation phenomenon associated with sexually 
explicit material. Pornography users continually escalate to "harder" material in order to maintain their baseline level of happiness. This is relevant to our work since it suggests that the effects of easier access to pornography are cumulative over time: the long-run effect on marriage is likely to be stronger than what we find in this paper.

Most existing research on pornography is generally qualitative and case-based. Nevertheless, our work is well-motivated by these studies, which aim to understand the characteristics of pornography users and its consequences on their behavior. Lo and Wei (2005) and Lam and Chan (2007) find that pornography usage is associated with a negative attitude towards women and with premarital sexual permissiveness generally, both of which suggest a negative association with marriage formation. Doring (2009) provides a comprehensive review and cautions that studies such as the two aforementioned cannot be interpreted in a causal way: individuals with such proclivities may be more likely to turn to pornography in the first place. Stack et al. (2004) is notable because the authors also use data from the General Social Survey to study the characteristics of pornography users. ${ }^{3}$ Using simple logistic regression, they find that pornography users are less likely to attend church, more likely to involve themselves in other deviant sexual behavior such as adultery and prostitution, and less likely to be involved in selfdescribed happy marriages. By contrast, Kendall (2007) uses state-level variation in availability of the Internet in its formative years to argue that accessibility of pornography via the Internet is associated with a decline in the incidence of rape. ${ }^{4}$

There is some work on the impact of pornography on existing marriages. Doran and Price (2014) show that adults who watch X-rated films are more likely to be unhappy in their

\footnotetext{
${ }^{3}$ This paper uses only the 2000 wave.

${ }^{4}$ The effect is particularly strong for teenagers, who cannot easily access non web-based pornography.
} 
marriages, more likely to have extra-marital affairs and more likely to divorce. Manning (2006) and Zitzman and Butler (2009) also argue that pornography consumption can reduce the happiness and stabilitiy associated with existing marriages. Manning, in particular, points to a number of factors that link pornography with marital instability, such as decreased sexual satisfaction and intimacy within marriage along with a perception by wives that pornography consumption constitutes a form of infidelity. These papers do not deal with marital formation specifically, although reducing the utility associated with marriage can impact marital formation for an agent who is forward rational when he is choosing whether to marry.

\section{Model}

In a simple one-period model where pornography consumption substitutes for marital sex, the effect of making pornography easier to access is straightforward. Cheaper pornography expands the budget set in the single state and so, if a man can choose whether to get married at the beginning of the period, higher utility from marriage is required in order for the man to marry. Thus, cheaper pornography is unequivocally associated with lower marriage rates.

In a more complete model, the effects are less straightforward. Consider a two-period model for a man who is single at the beginning of the first period that proceeds as follows. At the beginning of the first period, the man has an opportunity to marry. Utility in the single state is given by $U^{S}(x, z)$, where $x$ represents extra-marital sexual activities like pornography and $z$ represents other consumption. Utility in the married state is $U^{M}(x, z)+\theta$, where $\theta$ is maritalspecific utility. There is variance across potential wives in the level of $\theta$ produced for the 
husband. At the beginning of the second period, there is probability $\mu$ that first-period marriages will terminate in divorce.

The cost of extra-marital sexual activities is $p$ and the price of other consumption is normalized to 1 . One can think about the cost of extra-marital sexual activity as incorporating both pecuniary and non-pecuinary costs. For example, the cost of purchasing a pornographic magazine from a brick-and-mortar shop may involve stigma as well as a monetary cost, and the availability of Internet-based pornography can reduce both.

For the budget sets, income in the first period is $m_{1}$ and income in the second period is $m_{2}$. A single man claims all of this income. A married man in period $t$ claims income of $\alpha m_{t}$ for himself. We normally think of $\alpha<1$, although $\alpha>1$ is possible if there are strong economies of scale from multi-person households. ${ }^{5}$ A married man who divorces at the beginning of the second period pays a separation cost of $c$.

Appendix 1 outlines the solution to these constrained optimization problems and gives the associated indirect utilities. Figure 1 gives a graphical representation of the decision tree and the associated payoffs (in utils) each period, for a man in each state.

\section{$<<$ INSERT FIGURE 1 HERE>>}

The man chooses at the beginning of period 1 whether to marry. For decisions made at the beginning of period 1 , future payoffs are discounted at rate $\beta$. Assuming forward-rational

\footnotetext{
${ }^{5}$ The determination of the bargaining share $\alpha$ is an ongoing research area. In the extreme case, a higher-quality wife might not add any utility for the husband if she can claim all the surplus brought to the marriage by her own quality. Otherwise, when the surplus is split, there is a net increase in male utility associated with a higher-quality wife.
} 
expectations, he marries whenever $\theta$ is sufficiently large that his expected utility associated with marriage is greater than the utility associated with remaining single. Note that the former is stochastic because a man who chooses to marry is unsure whether divorce will occur between period 1 and period 2 . The mathematical appendix solves for the reservation spousal quality $\theta^{*}$ for a man to marry in the first period rather than remain single. Any change that raises $\theta^{*}$ reduces the marriage rate since it reduces the probability that a man will encounter a spouse who attains at least this level of quality.

An important point about this model is that we have allowed utility in both the single and married states to depend on extra-marital sexual activities $x$, like pornography. The marginal utilities associated with these activities may be different for single and married men, but pornography and marriage frequently coexist. With respect to the closely related case of prostitution, Friedman (2000) suggests that it may even be complementary to marital stability in some cases by giving sexually dissatisfied men an opportunity to pursue outside sexual opportunities. Empirically, Della Guista et al. (2009A) find that both categories of prostitution clients exist - men who use it as a substitute and as a complement with marriage.

We now proceed to discuss comparative statics for the impact of changes in the problem's parameters on marriage rates. We derive these results explicitly in appendix 1 . Increases in the man's bargaining share $\alpha$ increase the marriage rate, while increases in the separation cost $c$ reduce the marriage rate. The effect of income changes is ambiguous. Higher income contributes utility both in the single and in the married state. When $\alpha<1$, a married man claims less of an income increase than a single man does. However, total income available to the 
man is lower in this case, so whatever share of marginal income does accrue to the husband has higher marginal value. ${ }^{6}$

The key comparative static for our analysis is the impact on marriage rates of the cost $p$ of extra-marital sexual activities, inasmuch as the Internet has substantially decreased the cost associated with accessing pornography. This comparative static is ambiguous. Starting with the special case where extra-marital sexual activities are used only by single men, the comparative static is ambiguous even here. The reason is that cheaper pornography increases indirect utility not only for single men but also for divorcees. Further, divorcees' incomes are lowered by $c$, so the relaxation of the budget set from a reduction in $p$ has a higher marginal impact for them. Informally, cheaper pornography makes it easier to stay single, but it also makes it easier to get divorced. Thus, if divorce is likely, cheaper pornography could actually spur increases in the marriage rate by increasing the payoff in the event of a divorce. In the full model, there is an additional source of ambiguity. When we generalize to the possibility that pornography can coexist with marriage, then reductions in $p$ contribute explicitly to indirect utility both in the single state and in the married state. For which state the change has a greater marginal impact depends upon the marginal utilities and on the magnitude of differences in the man's disposable income in each state. In summary, the possibility of divorce and the potential for complementarities within marriage call into question our intuitive guess that making extramarital sexual opportunities easier to access necessarily reduces the marriage rate.

\footnotetext{
${ }^{6}$ There is an extensive literature on this point. Higher-income men do have higher marriage rates overall and are able to marry higher-quality spouses (Chiappori et al. 2012), but they might be delayed as more desirable men can afford to wait for better matches to materialize. See Weiss et al. (2009) for a detailed discussion of decision problems of this variety.
} 
Our solution to the model treats divorce probability $\mu$ as exogenous. This is not unreasonable given our context. Women initiate almost $70 \%$ of divorces in the United States (Brinig and Allen 2000), and even a male-initiated divorce for a forward-rational agent presumably comes from some stochastic shock that was unforeseen at the time of marriage. However, for our problem, we might think about the probability of divorce $\mu$ itself being a function of the level of extra-marital sexual gratification $x$ chosen by a married man. For example, Manning (2006) claims that many women view pornography consumption as a form of cheating, which could itself increase the probability of divorce. We argue in appendix 1 that the effect of marginal changes in $p$ is not impacted by this dependence as long as the optimal choice of $x$ depends "smoothly" on $p$. But for large, discrete changes in $p$, this dependence can create an additional dimension. Making pornography cheaper to access (weakly) increases a married man's choice of $x$, by revealed preference arguments, and thus increases the likelihood of divorce if pornography consumption is displeasing to the wife. Because divorce is costly, this in turn makes it less likely that a forward-rational man marries at all. Of course, Friedman (2000) suggests that the direction of the dependence of $\mu$ on $x$ is not straightforward. Making extramarital sexual opportunities easier to access may actually stabilize marriages by providing a backstop against unfulfilling marital sex.

\section{Data and Methods}

The data are from the 2000, 2002 and 2004 iterations of the General Social Survey (GSS). The GSS is a nationally representative survey of US residents. Detailed statistics on Internet usage were collected only for these years. Our sample consists of all men between the 
ages of 18 and 35, giving us a total of 1512 observations. Examining both men and women is problematic since it is generally understood that men and women face different incentives when making marital decisions. Furthermore, we focus on young men. This is not only because of the very steep age gradient in Internet usage, especially in the early years of the Internet, but also because this is the age range where men normally make a decision about marriage formation. Even in 2010, fewer than a quarter of men in the 35-39 age cohort had never been married (NCHS).

Our dependent variable of interest is a dummy with unit value for married respondents. The marriage variable is set equal to 0 for anyone who is not married at the time of the survey, whether because he has never been married or because he is divorced. We do not distinguish between divorcees and single men because it is increasingly difficult to make any meaningful distinction between unsuccessful marriages and cohabitation that fails to lead to marriage. Either one can be interpreted as a kind of trial period. ${ }^{7}$ Because the data are repeated cross-section rather than panel, we cannot say anything about whether the marriages our respondents have entered will continue to be stable. ${ }^{8}$ Nevertheless, the formation of a marriage is a necessary condition for the existence of a stable, lasting marriage. Thus, our object of interest is whether the instantaneous state is married or unmarried. While it may be the case that pornography can disrupt marriage, our research question relates to the formation of a marriage. $41 \%$ of our sample were married at the time of the survey.

\footnotetext{
7 The US Census Bureau reports that $9.1 \%$ of households from the 2000 census involved couples living together unmarried but in a "close personal relationship".

${ }^{8}$ It would be good to have panel data to explore the stability of marriages over time, but owing to the limits of our dataset the best we can do is to observe instantaneously whether the respondent is married. Doran and Price (2014) claim that pornography usage does destabilize existing marriages.
} 
Our two key independent variables of interest are the number of hours spent on the Internet each week and a dummy with unit value if the respondent self-reports having used the Internet to view pornography in the previous 30 days. We examine both measures for a few reasons. First, Internet use may be more accurately self-reported than pornography use. Previous literature suggests that a nontrivial portion of Internet use may be for pornography, even if the respondents are not willing to self-report. Second, the number of hours spent on the Internet gives us a continuous measure of intensity of usage, the mean being 5.44 hours per week. ${ }^{9}$ Finally, Internet usage might substitute for marriage in ways not related to pornography, like friendship or occupying time generally.

The other control variables are standard for models of marriage formation and dissolution. Age is obviously an important determinant of whether a man is married; the mean age in our sample is 27.4. For our income measure, we follow convention in using these data and take the midpoint of the reported category. The categories are quite narrow, especially for low incomes. We used $\$ 150,000$ for the top category; fewer than $1 \%$ of the sample are top-coded. College is a dummy set equal to 1 if the respondent holds a bachelor's degree or higher. Full Time is a dummy set equal to 1 if the respondent is employed full time. We also control for intensity of religious practice with the variable Attend, which is an increasing scale of attendance at religious services. Practice variables are more reliable than self-reported opinions in the social sciences since a person's choices are the best indicator of his preferences. Finally, in an attempt to control for personal characteristics that might incline a person more towards flexibility versus

\footnotetext{
${ }^{9}$ The variable on pornography usage does ask about the number of times it was used during the last 30 days (in 3 levels of usage categories), but frequency of use is presumably reported even less truthfully. In any case, we ran the regressions in the paper using an index of intensity of pornography usage rather than a dummy and the results were not much different.
} 
commitment in his decision-making, we include dummies measuring whether the respondent has moved to a different city within the same state or to a different state, relative to his location at age $16 .{ }^{10}$ About half of the respondents lived in the same place, with approximately one quarter each having moved to a different city within the same state and to a different state. People who are more mobile with respect to locational choices may also be more inclined to maintain flexibility in personal relationships.

We also look at other specific uses of the Internet besides pornography; the GSS asked about these uses in a series of 21 questions with the same structure as the pornography question. For example, $20 \%$ of respondents reported looking at news websites and $4 \%$ reported looking at religion websites. Summary statistics are reported in Table 1.

\section{$<<$ INSERT TABLE 1 HERE >>}

The equation of interest throughout is:

$$
\operatorname{Pr}(M A R=1)=\Phi\left(\beta_{0}+\beta_{1} \cdot \text { Internet }+\beta_{2} \cdot X_{\text {demo }}+u\right)
$$

Here, Internet is either hours spent on the Internet or a dummy for whether the respondent uses the Internet to look at pornography. $X_{\text {demo }}$ is a vector of the demographic characteristics indicated above. ${ }^{11}$

There is a potential for endogeneity in the equation of interest. One problem is simple reverse causation - married people presumably have fewer opportunities to look at pornography

\footnotetext{
${ }^{10}$ A variable that measured frequency of job changes is another option, but this is not available in the GSS.

${ }^{11}$ We also tried including a vector of time dummies $\delta_{t}$. But our sample covers only 5 years, and the results were almost the same.
} 
than single people do. Furthermore, marriage formation could be jointly determined together with Internet and pornography usage. Poor in-person social skills simultaneously drive Internet usage up and marriage probability down. Ease of divorce is another source of potential endogeneity. If divorce is low-cost, then the ability to get divorced easily could itself impact pornography usage, which in turn impacts the incentive to marry in the first place. ${ }^{12}$

In principle, we could address the endogeneity issues in the equation of interest with the use of instrumental variables. An ideal instrument would be exogenous characteristics of the area in which a respondent lives that impact Internet usage. Examples might be the weather or the cost of Internet access. Unfortunately, neither is available in the present dataset because the GSS codes responses only by four broad region designations, and has no locational information that is more specific.

We located two variables that we employ as instruments. While not fully free from endogeneity issues of their own, they potentially serve as a robustness check on the OLS and probit results. For hours of Internet usage as a determinant of marital status, we use the father's level of education as our instrument. For pornography viewing as a determinant of marital status, we use urbanization level as our instrument. ${ }^{13}$ Instrumental variables must satisfy both relevance and excludability conditions, and we now discuss the plausibility of our instruments with respect to these conditions.

First, instrumental variables must be relevant to the endogenous variables being instrumented. For hours of Internet usage, children of educated parents have access to more

\footnotetext{
${ }^{12}$ No-fault divorce laws are a potential source of heterogeneity across states. Unfortunately, GSS responses are not coded by state, so the data do not allow us to control for this.

${ }^{13}$ This is coded in the GSS as an index on a 1-10 declining scale of urbanization.
} 
technology and see parents who are curious about learning, and thus are more likely to use the Internet later on in life. The father's education level is a common instrument in the literature for his child's educational attainment, ${ }^{14}$ and our rationale for its use is along similar lines. For pornography viewing, different urbanization levels of the areas in which respondents live result in differences in the availability, speed and cost of Internet access. This obviously affects the cost of viewing pornography, which is bandwidth intensive. US Census Bureau reports show systematic differences in Internet access across urban and rural areas, especially during the formative years of the Internet. The relevance condition for instrumental variables is testable, and both instruments are reasonably strong. For hours of Internet usage, the first-stage OLS regression gives $F=12.84$ and for pornography usage, the first-stage OLS regression gives $F=$ 12.11. The standard diagnostic for weak instruments is $F<10$ in the first-stage regression, so both F-statistics are in the range for valid instrumental variables estimation. The full first-stage OLS regression results are given in appendix $2 .{ }^{15}$ The signs of the coefficients on the instruments are as expected. Increases in the father's education level are associated with more Internet use and living in a more rural area is associated with a lower frequency of pornography consumption.

The second condition is that instrumental variables must represent exogenous sources of variation for the variable being instrumented. Specifically for our case, this means that the instrumental variables should not be a direct causal factor for marriage (only via the endogenous variable) and also that they should be uncorrelated with the residual error in the equation of

\footnotetext{
${ }^{14}$ Well-cited examples are Trostel et al. (2002) and Solon (1992). The mother's level of education is another possibility, but it is substantially weaker.

${ }^{15}$ The F statistic from the first-stage regression is a standard diagnostic for two-stage least squares. But the firststage OLS results should be viewed as descriptive only for the other estimation methods used in the paper; their asymptotic properties as a diagnostic for estimation methods other than two-stage least squares are not established in the literature. This caveat is particularly true for pornography usage, which is binary.
} 
interest. In other words, the instrument should not be correlated with unexplained factors important for the decision to marry but that are not controlled for in our specification.

Excludability is not testable per se. It may be the case that a father's education level is itself a source of heterogeneity in marital propensity (e.g. genetics and parenting variations) and that these variations are correlated with unexplained factors in the decision to marry. But to the extent that it is not self-selected by the respondent, using it as an instrument can serve as a robustness check for the impact of hours of web usage on marital status, for which there is an even stronger endogeneity problem. Hours of web usage are actually self-selected by the respondent. In the case of the urbanization level, again this may be endogenous to marital formation because of self-selected migration related to social networking and job sorting. On the other hand, the location of many young people is exogenously determined by their parents. To the extent that urbanization provides some exogenous source of variation in web access and pornography usage, it is interesting to employ it as an instrument in supplement to the OLS and probit results. All in all, while our instruments are relevant, the argument for the excludability condition is weaker. Nevertheless, better instruments are not available in the dataset, and we use these instrumental variable to explore the robustness of our results to alternative specifications.

For instrumental variables estimation in the case where the dependent variable is binary, Greene (2008) suggests a hybrid instrumental variables / probit estimator where OLS is used for the first stage regression, and these estimates are inserted into a second-stage probit. The case of a binary dependent variable and a binary endogenous regressor is more problematic, and there is a substantial literature on this matter. Greene asserts that the IV/probit model is unreliable in this case because maximum likelihood estimation of the system uses a normal distribution for the 
errors, which is poorly motivated in the case of a dummy endogenous regressor. An alternative is the bivariate probit model, which uses full-information maximum likelihood to simultaneously estimate a system with a probit for both stages. However, Angrist (2001) argues that for the purpose of identifying the existence of a causal effect, simple linear models are preferable even in the case of dummy dependent variables, basically because linear models are more robust and because the mis-specification is more severe at extreme values than at moderate values.

\section{Results and Discussion}

Results for the regression of marital status on hours of Internet usage are given in Table 2. Results for the regression of marital status on pornography viewing are given in Table 3. In both cases, we show both probit and OLS estimates, following Angirst (2001) that linear models are more robust even if mis-specified. We have also included estimates that employ the instruments described in the previous section, including all three estimation techniques proposed for the case of the dummy endogenous variable. Robust standard errors are given. In addition, marginal effects for the independent variable of interest are given in brackets. These show the impact of a 1-unit increase in the relevant independent variable on the probability that an individual is married, with these marginal effects evaluated at the mean values of all independent variables.

$<<$ INSERT TABLE 2 HERE $>$

$<<$ INSERT TABLE 3 HERE >> 
For Internet usage generally, all models show a negative and statistically significant association between hours of web usage and marital status. The magnitude of the estimated marginal effect of an additional hour spent on the Internet on the probability that a man is married ranges from $-2.48 \%$ for the IV-probit model to $-0.19 \%$ for the OLS specification, but all are negative and significant at the $10 \%$ level. For pornography consumption specifically, the magnitude of the marginal effect also varies across models, but again all are negative and significant at the $10 \%$ level. Using the bivariate probit model, each $1 \%$ increase in propensity to look at pornography is associated with a $0.6 \%$ decline in the probability of being married. Across other models, the estimated marginal effect ranges from $0.07 \%$ to $5.3 \%$. ${ }^{16}$ This is not uncommon. Blundell and Powell (2004) find that estimates of marginal effects obtained from linear models may differ substantially in magnitude from those obtained using fitted models, but that the sign is generally correct. Thus, although the magnitude of the marginal effects differs across models, that they are all negative and significant is good evidence for the existence of an association in the claimed direction, according to Angrist. Limitations of the dataset do not allow us to conclusively state that we have identified the true causal effect, but we will argue below that our results suggest such an effect.

It is not surprising that the negative association between marriage and pornography specifically is stronger than the association between marriage and web usage generally since viewing pornography is a strict subset of Internet usage. Furthermore, the pornography users

\footnotetext{
16 These are for a small marginal change at the mean and obviously cannot be generalized over a large interval since the probit function is flattened at the extremes. For example, using the fitted probit function with mean values of other regressors, a discrete change from 0 to 1 in pornography viewing is associated with a $40 \%$ reduction in the probability of marriage for the bivariate probit estimates and an $8 \%$ reduction for the probit estimates without instruments.
} 
showing in our dataset are those who are willing to self-report using pornography. We would expect that those who are bold enough to self-report would be those for whom the strongest effects exist. The usefulness of estimating the effect of both Internet usage and pornography usage specifically is that some web usage is sure to be unreported pornography usage if rates of pornography consumption are anywhere close to what we reported in the introduction.

The coefficients on the other control variables largely have the expected signs. Marriage probability increases in age and increases in income. Men who are employed full time are also more likely to be married. The sign of the coefficient on attendance at religious services differs across the various specifications, but in the cases where it is significant at the $5 \%$ level, it has the expected sign - higher attendance at religious services is associated with increased probability of being married.

To think about whether these results have a causal interpretation, an interesting exercise is to compare the impact on marriage probability of using the Internet to view pornography versus using the Internet for other reasons. As discussed in the previous section, the GSS asks a series of parallel questions about several uses of the Internet besides looking at pornography. The marginal impact of these uses of the Internet on the probability of being married is shown in Table 4. We have used the bivariate probit model for this comparison, and all the relevant coefficients are significant at the 5\% level. With one exception, all of these marginal effects are negative, but none of them as strong as the marginal effect of pornography usage. This is consistent with our previous findings that Internet usage in general has a negative impact on marriage formation, but that use of pornography has an especially strong impact. In other words, our result is not just a selection effect dealing with characteristics of Internets users versus non- 
users. Interestingly, using the Internet to look at religious websites is positively associated with marriage probability, even controlling for attendance at religious services. This is a most informative contrast. Again, if the negative coefficient on pornography were simply a selection effect of Internet users versus non-Internet users that has not been controlled for, then there is no reason to expect that using the Internet for "wholesome" purposes would be associated with higher marriage probability. This positive coefficient amplifies our suggestion that the association we have detected is a causal impact of pornography consumption on marriage probability.

\section{<<INSERT TABLE 4 HERE $>>$}

As a second check on potential unobservable selection issues, we examine the level of selection on observables within the data among pornography users and nonusers. These sample statistics are given in Table 5. Pornography users are slightly younger, higher income, and less likely to be employed full time, although the difference in all cases is less than one fifth of one standard deviation. Pornography users are more likely to hold a college degree, more likely to have moved, and they also attend church less frequently, although the differential again is small - around one fourth of a standard deviation difference for holding a college degree and mobility, and slightly more than one third of a standard deviation difference for church attendance. At least based on observables, selection issues between pornography users and nonusers are not drastic. Of course, this is not conclusive about the nonexistence of some selection on unobservables, but 
it is at least suggestive that on important observable dimensions there are not large differences between pornography users and nonusers.

\section{<<INSERT TABLE 5 HERE >>}

\section{Conclusion}

Researchers often talk about how rapidly social change is disrupting what were once traditional family arrangements. But this really is an unsatisfying explanation since it begs us to understand the fundamentals that underlie these rapid social changes in the first place. There is no question that technological change is at the root of many of these social dynamics.

Declining rates of marriage formation and deteriorating stability of marriages that do form bring with them a multiplicity of demographic and socio-economic changes. Friedman (2000) argues that stable marriages create substantial welfare improvements for society, especially to the degree that marital stability produces high-quality children. As policymakers seek to understand and respond to these rapid changes in marital behavior, an awareness of the causal factors that lie behind them is crucial. In this paper, we have explored the possibility that the rapidly-proliferating Internet is in some way substitutable for marriage, especially to the extent that use of pornography can provide low-cost sexual gratification. If one of the important reasons to get married has a low-cost alternative, then it is natural to wonder about the extent to which one can replace the other.

The results in this paper suggest that such an association exists, and that it is potentially quite large. The deep causal factors that underlie the relationship between Internet usage and 
marriage formation are an interesting area for future research, but in this paper we have shown that the association exists and that the causality likely runs in the direction that we assert. We stop short of saying that we have accurately identified the magnitude of the causal effect. But the use of instruments, the contrast between pornography usage and other uses of the Internet and the lack of serious selection issues that distinguish pornography users from pornography non-users are all evidence that we have uncovered something real.

The policy implications of this work are manifold, especially given the rapid pace of technological innovation associated with the Internet. For developed countries, handheld and tablet devices continue to make Internet access more portable and universally integrated into day-to-day life, and the cost of this access continues to fall. A natural public policy option is web filtering. In 2013, the United Kingdom announced plans to require Internet Service Providers to block hard pornography by default, instead requiring customers to actively "opt in" if they want to access this content (BBC); the government is also requiring search engines to take additional steps to block illegal content, especially streaming video. As Kendall (2007) put it: "The arrival of the Internet caused a large decline in both the pecuniary and non-pecuniary costs of accessing pornography." While it is probably impossible to eliminate online access to pornography at this point, policies like those in the UK can at least increase the cost associated with accessing it. If the results in this paper are correct, policies along these lines have the potential to reduce pornography usage and increase marital entry, with its attendant welfare improvements.

For developing countries, researchers frequently note the speed with which demographic changes (e.g. declining birthrates) accompany rising living standards. Given the rapid decline in marital formation and stability in western countries, a natural question is how quickly this trend 
will proliferate in developing countries as their standards of living rise. Nowadays, widely available Internet access almost always accompanies rising living standards. Thus, the results in this paper suggest that technological proliferation and access to pornography specifically can be a causative factor that underlies these rapid demographic changes that occur concurrent to economic growth.

Economists can debate whether any public policy action can arrest the rapid social changes that we have seen in the past few decades, or even whether this is desirable. But we can never understand the evolution in social norms unless we understand the exogenous factors in our socio-economic environment that form the root causes of this evolution. 


\section{Figure 1: Decision Tree}
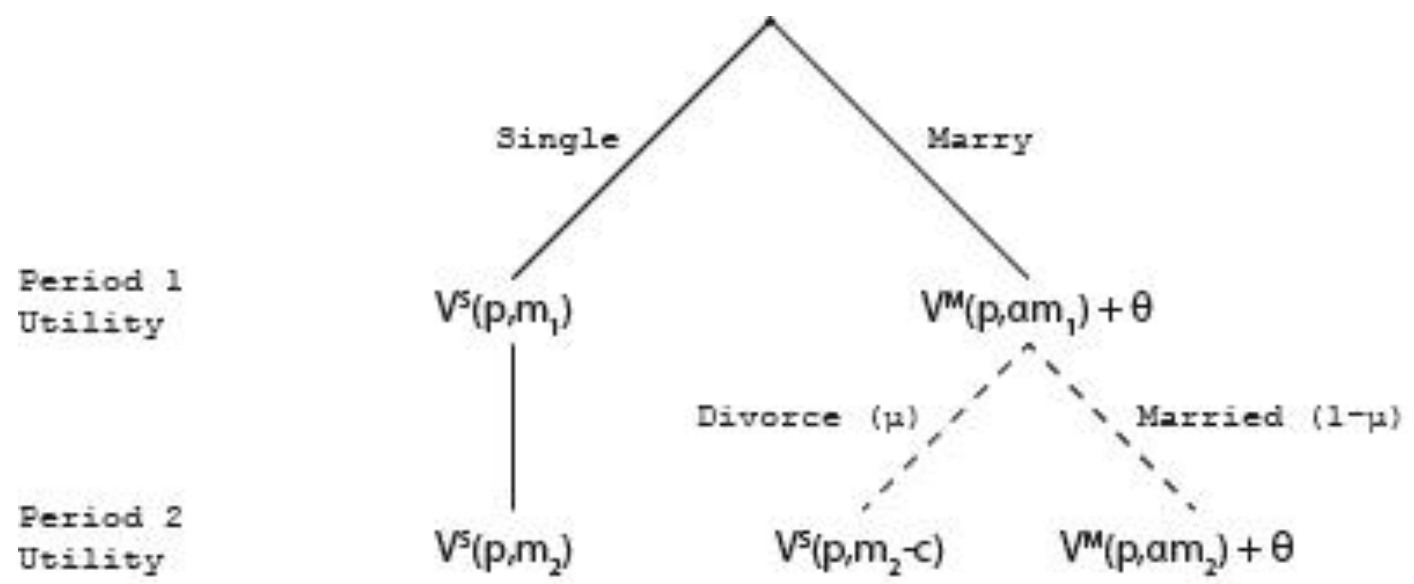

NOTES: Chart shows indirect utilities. Period 2 payoffs are discounted at rate $\beta$. Solid lines show decisions. Dashed lines show random moves by nature. 
Table 1: Descriptive Statistics

\begin{tabular}{lccccc}
\hline & Obs & Mean & Std. Deviation & Min & Max \\
\hline Married & 1512 & 0.41 & 0.49 & 0 & 1 \\
Age & 1512 & 27.4 & 4.86 & 18 & 35 \\
Income & 1512 & 26,400 & 25,832 & 0 & 150,000 \\
College & 1512 & 0.25 & 0.43 & 0 & 1 \\
Full Time & 1512 & 0.71 & 0.45 & 0 & 1 \\
Attend & 1499 & 2.91 & 2.44 & 0 & 8 \\
1 if Moved to different city & 1512 & 0.23 & 0.42 & 0 & 1 \\
1 if Moved to different state & 1512 & 0.26 & 0.44 & 0 & 1 \\
Hours on the Web & 1512 & 5.44 & 10.21 & 0 & 112 \\
Hours in chat rooms & 1507 & 0.23 & 1.60 & 0 & 32 \\
1 if Look at porn site & 1512 & 0.07 & 0.26 & 0 & 1 \\
1 if Look at finance site & 1512 & 0.13 & 0.34 & 0 & 1 \\
1 if Look at news site & 1512 & 0.20 & 0.40 & 0 & 1 \\
1 if Look at education site & 1512 & 0.14 & 0.35 & 0 & 1 \\
1 if Look at health site & 1512 & 0.11 & 0.32 & 0 & 1 \\
1 if Look at religious site & 1512 & 0.04 & 0.20 & 0 & 1 \\
1 if Look at sports site & 1512 & 0.16 & 0.37 & 0 & 1 \\
Father education & 1038 & 13.2 & 3.64 & 0 & 20 \\
Size of city & 1512 & 4.03 & 2.69 & 1 & 10 \\
\hline
\end{tabular}

NOTES: Sample includes all men between the ages of 18 and 35 from the 2000, 2002 and 2004 waves of the General Social Survey. 
Table 2: Hours Spent on the Internet Each Week as a Determinant of Marital Probability

\begin{tabular}{|c|c|c|c|}
\hline VARIABLES & & & \\
\hline Estimation Method & Probit & $O L S$ & IV-Probit \\
\hline Hours on the Web & $\begin{array}{c}-0.0065^{*} \\
(0.0038) \\
{[-0.0021]}\end{array}$ & $\begin{array}{c}-0.0019 * \\
(0.0011) \\
{[-0.0019]}\end{array}$ & $\begin{array}{c}-0.0710 * * * \\
(0.0241) \\
{[-0.0248]}\end{array}$ \\
\hline Age & $\begin{array}{c}0.1394 * * * \\
(0.0091)\end{array}$ & $\begin{array}{c}0.0431 * * * \\
(0.0025)\end{array}$ & $\begin{array}{c}0.1003 * * * \\
(0.0382)\end{array}$ \\
\hline Income & $\begin{array}{c}0.0059 * * * \\
(0.0017)\end{array}$ & $\begin{array}{c}0.0019 * * * \\
(0.0005)\end{array}$ & $\begin{array}{c}0.0059 * * * \\
(0.0019)\end{array}$ \\
\hline College & $\begin{array}{c}-0.3490 * * * \\
(0.0913)\end{array}$ & $\begin{array}{c}-0.1164 * * * \\
(0.0270)\end{array}$ & $\begin{array}{c}-0.0676 \\
(0.1939)\end{array}$ \\
\hline Full Time & $\begin{array}{c}0.4232 * * * \\
(0.0949)\end{array}$ & $\begin{array}{c}0.0987 * * * \\
(0.0264)\end{array}$ & $\begin{array}{c}0.1526 \\
(0.1759)\end{array}$ \\
\hline Attend & $\begin{array}{c}0.1041 * * * \\
(0.0153)\end{array}$ & $\begin{array}{c}0.0317 * * * \\
(0.0044)\end{array}$ & $\begin{array}{c}0.0821 * * \\
(0.0321)\end{array}$ \\
\hline Move City & $\begin{array}{c}0.1129 \\
(0.0931)\end{array}$ & $\begin{array}{c}0.0291 \\
(0.0273)\end{array}$ & $\begin{array}{l}0.1903 * \\
(0.0975)\end{array}$ \\
\hline Move State & $\begin{array}{l}0.1576 * \\
(0.0939)\end{array}$ & $\begin{array}{c}0.0407 \\
(0.0272)\end{array}$ & $\begin{array}{c}0.4091 * * * \\
(0.1056)\end{array}$ \\
\hline Constant & $\begin{array}{c}-4.8564 * * * \\
(0.2642)\end{array}$ & $\begin{array}{c}-0.9643 * * * \\
(0.0654)\end{array}$ & $\begin{array}{c}-3.1989 * * \\
(1.3814)\end{array}$ \\
\hline Observations & 1028 & 1028 & 1028 \\
\hline
\end{tabular}

NOTES: Coefficients are shown and robust standard errors are given in parentheses. * indicates significance at $10 \%$, $* *$ at $5 \%$ and $* * *$ at $1 \%$. Marginal effect is given in brackets for web hours, calculated at the mean. Sample includes all men between the ages of 18 and 35 from the 2000, 2002 and 2004 waves of the General Social Survey. 
Table 3: Pornography Viewing as a Determinant of Marital Probability

\begin{tabular}{|c|c|c|c|c|c|}
\hline VARIABLES & & & & & \\
\hline Estimation Method & Probit & $O L S$ & Bivariate Probit & IV-Probit & $T S L S$ \\
\hline Porn & $\begin{array}{c}-0.2390 * \\
(0.1463) \\
{[-0.0783]}\end{array}$ & $\begin{array}{c}-0.0685 * \\
(0.0387) \\
{[-0.0685]}\end{array}$ & $\begin{array}{c}-1.6562 * * * \\
(0.2050) \\
{[-0.6310]}\end{array}$ & $\begin{array}{c}-3.7608 * * * \\
(0.1666) \\
{[-1.2269]}\end{array}$ & $\begin{array}{c}-5.3209 * * \\
(2.6209) \\
{[-5.3209]}\end{array}$ \\
\hline Age & $\begin{array}{c}0.1340 * * * \\
(0.0090)\end{array}$ & $\begin{array}{c}0.0433 * * * \\
(0.0025)\end{array}$ & $\begin{array}{c}0.1239 * * * \\
(0.0096)\end{array}$ & $\begin{array}{c}0.0211 \\
(0.0156)\end{array}$ & $\begin{array}{c}0.0313 * * * \\
(0.0103)\end{array}$ \\
\hline Income & $\begin{array}{c}0.0057 * * * \\
(0.0017)\end{array}$ & $\begin{array}{c}0.0019 * * * \\
(0.0005)\end{array}$ & $\begin{array}{c}0.0049 * * * \\
(0.0016)\end{array}$ & $\begin{array}{c}0.0007 \\
(0.0013)\end{array}$ & $\begin{array}{c}0.0012 \\
(0.0018)\end{array}$ \\
\hline College & $\begin{array}{c}-0.3624 * * * \\
(0.0896)\end{array}$ & $\begin{array}{c}-0.1201 * * * \\
(0.0272)\end{array}$ & $\begin{array}{c}-0.2598 * * * \\
(0.0874)\end{array}$ & $\begin{array}{c}0.0947 \\
(0.0780)\end{array}$ & $\begin{array}{c}0.1216 \\
(0.1468)\end{array}$ \\
\hline Full Time & $\begin{array}{c}0.4315 * * * \\
(0.0950)\end{array}$ & $\begin{array}{c}0.1015 * * * \\
(0.0255)\end{array}$ & $\begin{array}{c}0.3877 * * * \\
(0.0900)\end{array}$ & $\begin{array}{c}0.1038 \\
(0.0762)\end{array}$ & $\begin{array}{c}0.1217 \\
(0.0881)\end{array}$ \\
\hline Attend & $\begin{array}{c}0.1023 * * * \\
(0.0152)\end{array}$ & $\begin{array}{c}0.0311 * * * \\
(0.0044)\end{array}$ & $\begin{array}{c}0.0774 * * * \\
(0.0151)\end{array}$ & $\begin{array}{l}-0.0195 \\
(0.0139)\end{array}$ & $\begin{array}{l}-0.0272 \\
(0.3072)\end{array}$ \\
\hline Move City & $\begin{array}{c}0.1034 \\
(0.0934)\end{array}$ & $\begin{array}{c}0.0268 \\
(0.0278)\end{array}$ & $\begin{array}{l}0.1597 * \\
(0.0898)\end{array}$ & $\begin{array}{c}0.1876 * * * \\
(0.0697)\end{array}$ & $\begin{array}{c}0.2612 \\
(0.1613)\end{array}$ \\
\hline Move State & $\begin{array}{c}0.1276 \\
(0.0897)\end{array}$ & $\begin{array}{c}0.0342 \\
(0.0265)\end{array}$ & $\begin{array}{l}0.1543 * \\
(0.0853)\end{array}$ & $\begin{array}{l}0.1332 * \\
(0.0660)\end{array}$ & $\begin{array}{c}0.1866 \\
(0.1205)\end{array}$ \\
\hline Constant & $\begin{array}{c}-4.8734 * * * \\
(0.2603)\end{array}$ & $\begin{array}{c}-0.9700 * * * \\
(0.0560)\end{array}$ & $\begin{array}{c}-4.2181 * * * \\
(0.2865)\end{array}$ & $\begin{array}{l}-0.4968 \\
(0.5268)\end{array}$ & $\begin{array}{l}-0.2206 \\
(0.4375)\end{array}$ \\
\hline Observations & 1499 & 1499 & 1499 & 1499 & 1499 \\
\hline
\end{tabular}

Notes: Coefficients are shown and robust standard errors are given in parentheses. * indicates significance at $10 \%$, ** at $5 \%$ and $* * *$ at $1 \%$. Marginal effect is given in brackets for porn usage dummy, calculated at the mean. Sample includes all men between the ages of 18 and 35 from the 2000,2002 and 2004 waves of the General Social Survey. 
Table 4: Different Internet Uses as Determinants of Marital Probability

\begin{tabular}{lc}
\hline Use of Internet & $\begin{array}{c}\text { Marginal Effect on } \\
\text { Marriage Probability }\end{array}$ \\
\hline Porn Site & -0.6310 \\
Finance Site & -0.5889 \\
News Site & -0.5877 \\
Education Site & -0.5823 \\
Health Site & -0.5744 \\
Sports Site & -0.5928 \\
Religious Site & 0.5399 \\
\hline
\end{tabular}

NOTES: Marginal effects calculated based on a bivariate probit model with the same specification and control variables as in Table 3 Marginal effects are evaluated at the mean. All corresponding coefficients are significant at the $1 \%$ level. 
Table 5: Characteristics of Pornography Users versus Pornography Non-Users

\begin{tabular}{lcc}
\hline Variable & $\begin{array}{l}\text { Pornography } \\
\text { Users }\end{array}$ & $\begin{array}{c}\text { Pornography } \\
\text { Non-Users }\end{array}$ \\
\hline Mean Age & 27.06 & 27.50 \\
Mean Income & 26,504 & 26,392 \\
$\begin{array}{l}\text { Proportion with College } \\
\text { Degree }\end{array}$ & 0.3565 & 0.2513 \\
$\begin{array}{l}\text { Proportion Employed Full } \\
\text { Time }\end{array}$ & 0.7130 & 0.7173 \\
$\begin{array}{l}\text { Mean Level of Church } \\
\text { Attendance (1-7 } \\
\text { increasing scale) }\end{array}$ & 2.0870 & 2.9848 \\
$\begin{array}{l}\text { Proportion Moved to a } \\
\text { Different City (same state) }\end{array}$ & 0.3130 & 0.2241 \\
$\begin{array}{l}\text { Proportion Moved to a } \\
\text { Different State }\end{array}$ & 0.3043 & 0.2577 \\
& & \\
\hline
\end{tabular}

NOTES: Sample includes all men between the ages of 18 and 35 from the 2000, 2002 and 2004 waves of the General Social Survey. 


\section{Appendix 1: Mathematical Results from Section III}

The utility function for a single man is $U^{S}(x, z)$, where $x$ represents extra-marital sexual activities and $z$ represents other consumption. The utility function is concave and increasing in both arguments. The price of consumption $z$ is normalized to 1 and the cost of extra-marital sexual activities is $p$. When income is $m$, a single man solves the following constrained maximization problem:

$$
\max U^{S}(x, z) \text { s.t. } p x+z \leq m
$$

The corresponding indirect utility function $V^{S}(p, m)$ gives the maximized value of utility. It is increasing in $m$ but decreasing in $p$.

The utility function for a married man is $U^{M}(x, z)+\theta$, where $\theta$ is nonpecuniary utility specific to marriage. The utility function $U^{M}(x, z)$ is also assumed to be concave and increasing in both arguments, although the marginal utility of $x$ may be different than that for a single man. A married man solves a similar constrained maximization problem to that given above, and his corresponding indirect utility function is $V^{M}(p, m)+\theta$.

Recall that income in the first period is $m_{1}$ and income in the second period is $m_{2}$. Where future payoffs are discounted at rate $\beta$, a man who chooses not to marry enjoys lifetime utility:

$$
V_{\text {lifetime }}^{S}=V^{S}\left(p, m_{1}\right)+\beta V^{S}\left(p, m_{2}\right)
$$

For men who marry, their monetary income available for consumption is $\alpha m$. Thus, men who marry and remain married through the second period enjoy lifetime utility:

$$
V_{\text {lifetime }}^{M, M}=V^{M}\left(p, \alpha m_{1}\right)+\theta+\beta\left[V^{M}\left(p, \alpha m_{2}\right)+\theta\right]
$$


Men who marry but divorce in the second period face a cost of $c$ associated with divorce, reducing their incomes, which generates lifetime utility of:

$$
V_{\text {lifetime }}^{M, D}=V^{M}\left(p, \alpha m_{1}\right)+\theta+\beta\left[V^{S}\left(p, m_{2}-c\right)\right]
$$

Thus, where divorce occurs with probability $\mu$, expected lifetime utility at the beginning of period 1 for a man who chooses to marry is:

$$
\begin{aligned}
E V_{\text {lifetime }}^{M} & =\mu V_{\text {lifetime }}^{M, D}+(1-\mu) V_{\text {lifetime }}^{M, M} \\
& =V^{M}\left(p, \alpha m_{1}\right)+(1+\beta(1-\mu)) \theta+\mu \beta V^{S}\left(p, m_{2}-c\right)+(1-\mu) \beta V^{M}\left(p, \alpha m_{2}\right)
\end{aligned}
$$

An expected utility maximizer will marry during the first period whenever $E V_{\text {lifetime }}^{M}$ exceeds $V_{\text {lifetime }}^{S}$. Solving this inequality, the minimal level of marital utility $\theta$ that justifies marriage is:

$$
\theta^{*}=\left(\frac{1}{1+\beta(1-\mu)}\right)\left(V^{S}\left(p, m_{1}\right)+\beta V^{S}\left(p, m_{2}\right)-V^{M}\left(p, \alpha m_{1}\right)-(1-\mu) \beta V^{M}\left(p, \alpha m_{2}\right)-\mu \beta V^{S}\left(p, m_{2}-c\right)\right)
$$

Anything that increases threshold spousal quality $\theta^{*}$ leads to a decline in marital probability (the probability that a single man will encounter a potential mate who satisfies the threshold), and conversely anything that reduces threshold quality level $\theta^{*}$ leads to more marriage.

The marginal effect of an increase in the cost of paid sexual activities $p$ on threshold spousal quality level is:

$$
\frac{\partial \theta^{*}}{\partial p}=\left(\frac{1}{1+\beta(1-\mu)}\right)\left(\frac{\partial V^{S}\left(p, m_{1}\right)}{\partial p}+\beta \frac{\partial V^{S}\left(p, m_{2}\right)}{\partial p}-\frac{\partial V^{M}\left(p, \alpha m_{1}\right)}{\partial p}-(1-\mu) \beta \frac{\partial V^{M}\left(p, \alpha m_{2}\right)}{\partial p}-\mu \beta \frac{\partial V^{S}\left(p, m_{2}-c\right)}{\partial p}\right)
$$

This can be either positive or negative, because an increase in $p$ has marginal effects on the utility of both single and married men. For a benchmark case, let us begin by assuming that only single men use pornography (i.e. that marital sex is a perfect substitute for pornography). In that case, the marginal effect is: 


$$
\frac{\partial \theta^{*}}{\partial p}=\left(\frac{1}{1+\beta(1-\mu)}\right)\left(\frac{\partial V^{S}\left(p, m_{1}\right)}{\partial p}+\beta \frac{\partial V^{S}\left(p, m_{2}\right)}{\partial p}-\mu \beta \frac{\partial V^{S}\left(p, m_{2}-c\right)}{\partial p}\right)
$$

Even in this case, the sign of the derivative is ambiguous. A reduction in the value of $p$ raises the value of being single but it also raises the value of being divorced. Since income is reduced by $c$ as a result of divorce, concavity of the utility function implies that the marginal utility of a reduction in $p$ has a stronger impact for a divorced single man than for a never-married single man. Thus, when divorce is expensive and likely, a reduction in the cost of pornography can increase the man's propensity to marry by making it less costly to get divorced.

In the more general model, where paid sexual activities $x$ can contribute utility both for divorce and for marriage, there are additional ambiguities in the sign of the comparative static because a reduction in $p$ can add to utility both for married and single men.

For the other comparative statics, inspection of the expression for threshold quality $\theta^{*}$ shows that it is declining in bargaining share $\alpha$ but increasing in separation cost $c$. The impact of changes in income is ambiguous in income from both periods. Precisely:

$$
\begin{gathered}
\frac{\partial \theta^{*}}{\partial m_{1}}=\left(\frac{1}{1+\beta(1-\mu)}\right)\left(\frac{\partial V^{S}\left(p, m_{1}\right)}{\partial m_{1}}-\frac{\partial V^{M}\left(p, \alpha m_{1}\right)}{\partial m_{1}}\right) \\
\frac{\partial \theta^{*}}{\partial m_{2}}=\left(\frac{\beta}{1+\beta(1-\mu)}\right)\left(\frac{\partial V^{S}\left(p, m_{2}\right)}{\partial m_{2}}-(1-\mu) \frac{\partial V^{M}\left(p, \alpha m_{2}\right)}{\partial m_{2}}-\mu \frac{\partial V^{S}\left(p, m_{2}-c\right)}{\partial m_{2}}\right)
\end{gathered}
$$

Higher income contributes utility both to married and to single people. Married people typically are able to consume only a lower share of their incomes (when $\alpha<1$ ), but whatever share they do claim has higher marginal value.

In the body of the paper, we have raised the possibility that the divorce probability $\mu$ may not be exogenous, but may itself be a function of a married man's consumption of extra-marital sexual opportunities. Precisely, $\mu\left(x_{1}^{m}\right)$ depends on a married man's choice of $x$ in the first period 
during which he is married. Thus, $\mu$ depends indirectly on $p$ since the maximized value of paid sexual activity $x^{*}$ for a married man is itself a function of $p$. For a small, marginal change in $p$, the envelope theorem allows us to ignore this indirect effect in computing the derivative, and the results will be the same as above (as long as the dependence is smooth). We discuss discrete changes heuristically in section III. 


\section{Appendix 2: First-Stage OLS Regression Results}

\begin{tabular}{|c|c|c|c|}
\hline Hours on the Web & & Pornography Viewing & \\
\hline Father Education & $\begin{array}{c}0.2684 * * * \\
(0.0897)\end{array}$ & Size of City & $\begin{array}{l}-0.0040 * \\
(0.0022)\end{array}$ \\
\hline Age & $\begin{array}{c}-0.1559 * * \\
(0.0731)\end{array}$ & Age & $\begin{array}{l}-0.0018 \\
(0.0014)\end{array}$ \\
\hline Income (thousands) & $\begin{array}{c}0.0317 * * \\
(0.0145)\end{array}$ & Income (thousands) & $\begin{array}{c}-0.0012 \\
(0.0030)\end{array}$ \\
\hline College & $\begin{array}{c}2.5002 * * * \\
(0.7601)\end{array}$ & College & $\begin{array}{c}0.0533 * * * \\
(0.0185)\end{array}$ \\
\hline Full Time & $\begin{array}{c}-1.9836^{* *} \\
(0.7739)\end{array}$ & Full Time & $\begin{array}{l}-0.0002 \\
(0.0156)\end{array}$ \\
\hline Attend & $\begin{array}{l}-0.0829 \\
(0.1251)\end{array}$ & Attend & $\begin{array}{c}-0.0106 * * * \\
(0.0024)\end{array}$ \\
\hline Move City & $\begin{array}{c}1.0793 \\
(0.7454)\end{array}$ & Move City & $\begin{array}{c}0.0190 \\
(0.0181)\end{array}$ \\
\hline Move State & $\begin{array}{c}3.1386 * * * \\
(0.7654)\end{array}$ & Move State & $\begin{array}{c}0.0053 \\
(0.0168)\end{array}$ \\
\hline Constant & $\begin{array}{c}2.7074 \\
(2.3766)\end{array}$ & Constant & $\begin{array}{c}0.2051 * * * \\
(0.0418)\end{array}$ \\
\hline Observations & 1028 & & 1499 \\
\hline $\mathrm{F}$ & 12.84 & & 12.11 \\
\hline
\end{tabular}

NOTES: Coefficients are shown and robust standard errors are given in parentheses. * indicates significance at $10 \%$, $* *$ at $5 \%$ and $* * *$ at $1 \%$. Sample includes all men between the ages of 18 and 35 from the 2000, 2002 and 2004 waves of the General Social Survey. 


\section{References}

Angrist, Joshua D. (2001). Estimation of Limited Dependent Variable Models with Dummy Endogenous Regressors. Journal of Business and Economic Statistics 19: 2-28.

Blundell, Richard W. and Powell, James L. (2004). Endogeneity in Semiparametric Binary Response Models. The Review of Economic Studies 71: 655-679.

Brinig, Margaret F. and Allen, Douglas W. (2000). 'These Boots are Made for Walking': Why Most Divorce Filers are Women. American Law and Economics Review 2: 126-169.

Cameron, Samuel and Collins, Alan (2003). Estimates of a Model of Male Participation in the Market for Female Heterosexual Prostitution Services. European Journal of Law and Economics 16: $271-288$.

Carroll, Jason S., Padilla-Walker, Laura M., Nelson, Larry J., Olson, Chad D., McNamara Barry, Carolyn and Madsen, Stephanie D. (2008). Generation XXX: Pornography Acceptance and Use Among Emerging Adults. Journal of Adolescent Research 23: 6-30.

Cunningham, S. and Kendall, T. D. (2011). Prostitution 2.0: The changing face of sex work. Journal of Urban Economics 69: 273-287.

Della Giusta, Marina, Di Tommaso, Maria Laura, Shima, Isilda and Strom, Steinar (2009). What Money Buys: Clients of Street Sex Workers in the US. Applied Economics 41: 2261-2277.

Della Giusta, Marina, Di Tommaso, Maria Laura, and Strom, Steinar (2009). Who is Watching? The Market for Prostitution Services. Journal of Population Economics 22: 501-516.

Doran, Kirk, and Price, Joseph (2014). "Pornography and Marriage." Forthcoming in Journal of Family and Economic Issues.

Doring, Nicola M. (2009). The Internet's Impact on Sexuality: A Critical Review of 15 Years of Research. Computers in Human Behavior 25: 1089-1101.

D’Orlando, Fabio (2011). The Demand for Pornography. Journal of Happiness Studies 12: 5175 .

Edlund, Lena and Korn, Evelyn. (2002). A Theory of Prostitution. Journal of Political Economy 110: $181-214$.

Finer, Lawrence B. (2007). Trends in Premarital Sex in the United States, 1954-2003. Public Health Reports 122: 73-78.

Forbes (2011). How Much of the Internet Is Actually for Porn? 
Friedman, David D. (2000). Law's Order: What Economics Has to Do with Law and Why It Matters. Princeton: Princeton University Press.

Greene, William H. (2008) Econometric Analysis. Upper Saddle River: Pearson.

Kendall, Todd D. (2007). Pornography, Rape and the Internet. Online.

http://obu-investigators.com/xuk/porn/clemson/kendall.pdf

Lam, Chun Bun and Chan, Darius K.S. (2007). The Use of Cyberpornography by Young Men in Hong Kong: Some Psychosocial Correlates. Archives of Sexual Behavior 36: 588-598.

Lo, Ven-Hwei and Wei, Ran (2005). Exposure to Internet Pornography and Taiwanese Adolescents' Sexual Attitudes and Behavior. Journal of Broadcasting and Electronic Media 49: 221-237.

Manning, Jill C. (2006). The Impact of Internet Pornography on Marriage and the Family: A Review of the Research. Sexual Addiction and Compulsivity 13: 131-165.

National Center for Health Statistics. National Vital Statistics Reports (various years). Online. http://www.cdc.gov/nchs/mardiv.htm.

National Opinion Research Center. General Social Survey (various years). Online. http://webapp.icpsr.umich.edu/GSS/.

Online pornography to be blocked by default, PM announces (2013, July 22). BBC. Online http://www.bbc.com/news/uk-23401076

Pitts, Marian K., Smith, Anthony M.A., Grierson, Jeffrey, O’Brien, Mary and Misson, Sebastian (2004). Who Pays for Sex and Why? An Analysis of Social and Motivational Factors Associated with Male Clients of Sex Workers. Archives of Sexual Behavior 33: 353-358.

Solon, Gary (1992). Intergenerational Income Mobility in the United States. The American Economic Review 82: 393-408.

Stack, Steven, Wasserman, Ira and Kern, Roger (2004). Adult Social Bonds and Use of Internet Pornography. Social Science Quarterly 85: 75-88.

Thorbek, Susanne and Pattanaik, Bandana Eds. (2002). Transnational Prostitution: Changing Global Patterns. London: Zed Books.

Trostel, Philip, Walker, Ian and Woolley, Paul (2002). Estimates of the Economic Return to Schooling for 28 Countries. Labour Economics 9: 1-16. 
U.S. Census Bureau. Statistical Abstract of the United States (various years). Online. http://www.census.gov/statab/www/.

U.S. Census Bureau (2003). Married-Couple and Unmarried-Partner Households: 2000.

Van Landingham, Mark J., Suprasert, Somboon, Sittitrai, Werasit, Vaddhanaphuti, Chayan and Grandjean, Nancy (1993). Sexual Activity among Never-Married Men in Northern Thailand. Demography 30: 297-313.

Zitzman, Spencer T. and Butler, Mark H. (2009). Wives' Experience of Husbands' Pornography Use and Concomitant Deception as an Attachment Threat in the Adult Pair-Bond Relationship. Sexual Addiction and Compulsivity 16: 210-240. 